A new larval host record for Sphingomorpha chlorea (Cramer) (Insecta: Lepidoptera: Noctuidae) from Karnataka, India

\author{
Ankita Gupta ${ }^{1}$ \& Peter Smetacek ${ }^{2}$ \\ ${ }^{1}$ National Bureau of Agriculturally Important Insects, Post Bag \\ No. 2491, H.A. Farm Post, Bellary Road, Hebbal, Bengaluru, \\ Karnataka 560024, India \\ ${ }^{2}$ Butterfly Research Centre, The Retreat, Jones Estate, P.O. \\ Bhimtal, Nainital, Uttarakhand 263136, India \\ Email: ${ }^{1}$ drankitagupta7@gmail.com (corresponding author), \\ 2 petersmetacek@rediffmail.com
}

Sphingomorpha chlorea (Cramer, 1777) is a widespread noctuid, known to occur over most of the mainland Old World Tropics. It belongs to a group of moths that are known to indulge in the habit of fruit piercing, a practice that causes considerable damage to orchards in Southeast Asia and Africa. In addition to its fondness for fruit on the tree, it is also attracted to fermented fruit, beer, spirits and other sources of sugars. As a result, it is called the Sundowner Moth and the Banana Hawk in parts of Africa.

The moth is of minor importance to agriculture on account of its abovementioned habits. Besides this, the larva is eaten in many parts of its African range. Unlike other edible larvae, it is not an article of commerce since it loses flavour when it is dried. Hence, it is eaten fresh in rural areas where it occurs

Date of publication (online): 26 February 2011

Date of publication (print): 26 February 2011

ISSN $0974-7907$ (online) | 0974-7893 (print)

Editor: B.A. Daniel

\section{Manuscript details:}

Ms \# 02564

Received 09 September 2010

Final received 09 December 2010

Finally accepted 21 December 2010

Citation: Gupta, A. \& P. Smetacek (2011). A new larval host record for Sphingomorpha chlorea (Cramer) (Insecta: Lepidoptera: Noctuidae) from Karnataka, India. Journal of Threatened Taxa 3(2): 1553-1554.

Copyright: (c) Ankita Gupta \& Peter Smetacek 2011. Creative Commons Attribution 3.0 Unported License. JoTT allows unrestricted use of this article in any medium for non-profit purposes, reproduction and distribution by providing adequate credit to the authors and the source of publication.

Acknowledgements: The first author is grateful to Dr. R.J. Rabindra, Director, NBAll, Bengaluru for providing the necessary facilities for carrying out this research work.

\section{OPEN ACCESS | FREE DOWNLOAD}

in large numbers in some years (Silow 1976). Although the possibility exists that this moth's larva forms a part of the diet of humans in parts of Asia where lepidopteran larvae are routinely consumed, it has not been reported in the literature so far.

\section{Materials and Methods}

In the course of searching for egg and larval parasites of Lepidoptera in the forest of Savandurga, Karnataka $\left(12^{0} 55^{\prime} 10.75^{\prime}\right.$ 'N \& $77^{0} 17^{\prime} 34.37^{\prime \prime}$ ) a fleshy green caterpillar was discovered feeding on Lantana camara Linnaeus (Verbenaceae) on 07 June 2010 (Image 1). It was collected and reared in the laboratory where, in due course it pupated (Image 2) and on 15 July 2010, a noctuid moth emerged. It was identified as Sphingomorpha chlorea (Cramer) (Image 3). The specimen is in the collection of National Bureau of Agriculturally Important Insects, Bangalore (Reg.No. Lep/Sph/ch-6/10).

Perusal of the literature (Sevastopulo 1941;

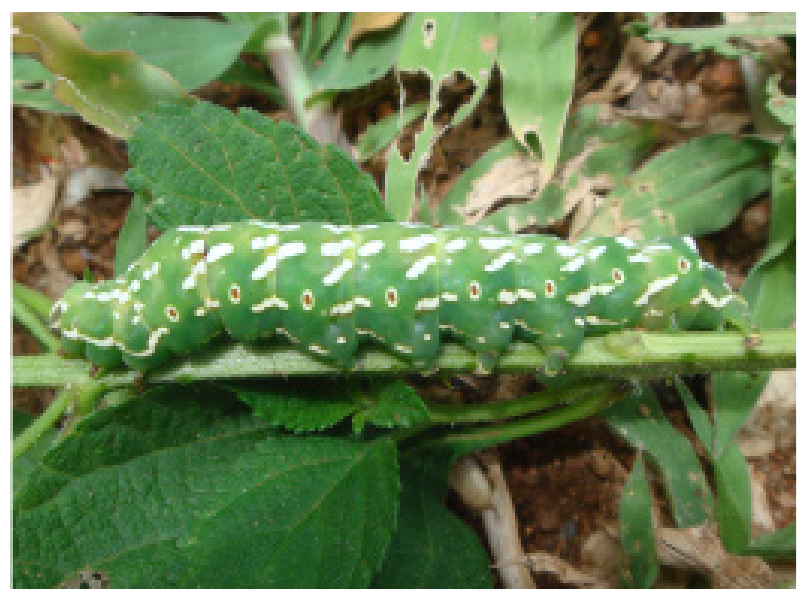

Image 1. Sphingomorpha chlorea caterpillar, lateral view

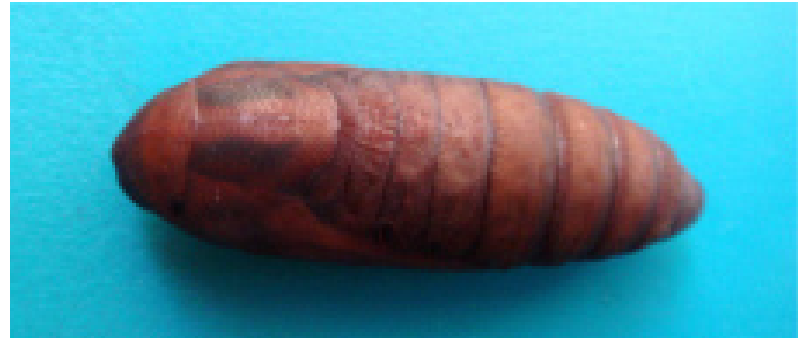

Image 2. Sphingomorpha chlorea pupa 


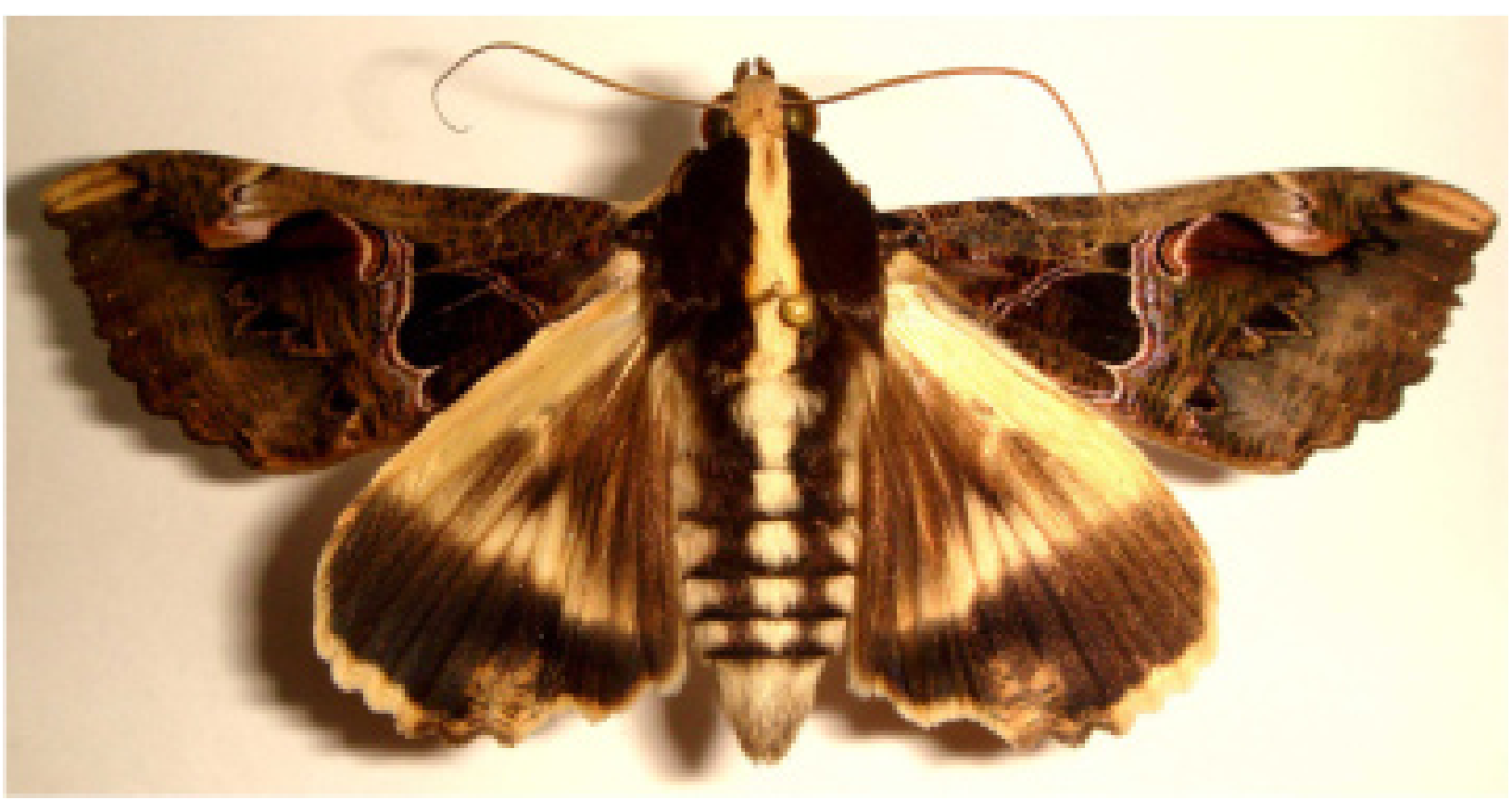

Image 3. Adult moth of Sphingomorpha chlorea (Cramer)

Sevastopulo 1949; Robinson et al. 2001) clarified that this was an unreported host plant for the moth. Hence, it is reported here.

\section{Discussion}

This species is widespread and common in tropical Africa, whereas it is more local and rarer in Asia. Therefore, the economic importance may be different in the two continents. The distribution in the southern parts of the Arabian Peninsula indicates a more or less coherent distribution over these two continents. It is unlikely that Sphingomorpha chlorea was introduced in Asia quite recently, as a closely related species occurs in Java (Sphingomorpha hemia).

Sphingomorpha chlorea has been recorded on four different larval host plants in the Oriental Region. These are Sclerocarya caffra (Anacardiaceae), Acacia (Leguminosae), Malus pumila (Rosaceae) and Citrus (Rutaceae) (Robinson et al. 2001). The present record thus not only adds a new larval host plant species, but also represents an addition to the known plant families that this species feeds upon, Verbenaceae.

The adaptation of this moth to an exotic plant like Lantana camara, which is a native of tropical America (Polunin \& Stainton 1984) is of interest, since $L$. camara is now a widespread naturalized plant in India. It occurs in many places from where $S$. chlorea (Cramer) has not been reported, like the plains of Uttar Pradesh, Uttarakhand, Himachal Pradesh, etc. It remains to be seen whether the moth spreads to the above mentioned sub-tropical localities in the years to come or whether it is indeed restricted to the tropics by other factors, perhaps climatic.

\section{REFERENCES}

Polunin, O. \& A. Stainton (1984). Flowers of the Himalaya. Oxford University Press, Delhi, 579pp+128pl.

Robinson, G.S., P.R. Ackery, I.J. Kitching, G.W. Beccaloni \& L. Hernandez (2001). Hostplants of the Moth and Butterfly Caterpillars of the Oriental Region. The Natural History Museum and Southdene Sdn Bhd., London and Kuala Lumpur, 744pp.

Sevastopulo, D.G. (1941). On the food-plants of Indian Agaristidae and Noctuidae (Heterocera). Journal of the Bombay Natural History Society 42: 421-430.

Sevastopulo, D.G. (1949). A supplementary list of the food-plants of the Indian Bombycidae, Agaristidae and Noctuidae. Journal of the Bombay Natural History Society 48: 265-276.

Silow, C.A. (1976). Edible and Other Insects of Mid-western Zambia. Studies in Ethno-entomology II. Occasional Papers V. Institutionen för Allmän och Jämförande Etnografi vis, Uppssala Universitet. Uppsala, Sweden: Almqvist \& Wiksell, 223pp. 